\title{
Integration of Endogenous Development Theory into the Study of Seed Governance
}

\section{Yoshiaki Nishikawa}

\begin{abstract}
In the 1970s, the Japanese sociologist Kazuko Tsurumi developed endogenous development theory - the idea of 'development from within', which frames human wellbeing, ecological viability and community agency as central to sustainable modernisation. In this study of Tsurumi's ideas vis-à-vis seed governance, Yoshiaki Nishikawa first traces the broader debate over seed systems, from polarised stances such as traditional vs modern to more nuanced mixed approaches. Nishikawa shows how Tsurumi's thinking on values, communication, local autonomy and tradition can illuminate understanding of humanity's relationship with seeds across cultures and regions. Many farmers, for instance, consider crop diversity and seed production as naturally integral to their stewardship of local ecologies, rather than politicised acts of sovereignty. Wise governance is based on an understanding of seeds as a biocultural legacy, and ensures that autonomy and respect are interwoven in the concept and practice of seed sovereignty.
\end{abstract}

Y. Nishikawa $(\bowtie)$

Ryukoku University, Kyoto, Japan

e-mail: nishikawa@econ.ryukoku.ac.jp

(C) The Author(s) 2022

Y. Nishikawa and M. Pimbert (eds.), Seeds for Diversity and Inclusion, https://doi.org/10.1007/978-3-030-89405-4_3 
Keywords Endogenous development $\cdot$ Kazuko Tsurumi · Nara Document of Authenticity - Seed governance - Sustainable livelihoods approach

\subsection{INTRODUCTION}

This book has two objectives. One is to expand the understanding and application of agroecology and food sovereignty concepts, with an emphasis on the Asian context. The other is to render debates on mainstreaming agroecology and food sovereignty more diverse and inclusive.

Along with flourishing ecosystems and inter-species diversity, crop biodiversity is central to agroecology, and crucial in ensuring the sustainability of crop farming and food production. Diversity in crop species has been created by farmers themselves, especially those engaged in socalled traditional agriculture as practised in developing countries (Harlan, 1992). In this way, farmers directly contribute to the UN Sustainable Development Goal 15, 'Life on Land', which aims to protect, restore and promote the sustainable use of biodiversity.

This chapter introduces endogenous development theory, originally developed by a Japanese sociologist Kazuko Tsurumi in the 1970s and other researchers, mainly during the 1980s and 1990s, to help develop thinking on agroecology and sovereignty vis-à-vis the realities of rural communities, especially in terms of diversity and inclusion (see Chapter 1 , Box 1.2). Focusing on the role of autonomous actors in resource management, and more generally on the importance of achieving a more harmonious relationship with nature, the chapter evaluates seed systems in which livelihoods are rooted in understanding of the surrounding environment and of humanity as part of it.

\subsection{A BRIEF History of the Debates on Seed Systems}

Crop-breeding institutions-most of which focus on biological science and the industrialisation of agriculture-are mainly concerned with obtaining sufficient diversity in terms of breeding materials. Their aim with conservation and the management of seeds as crop genetic resources 
is primarily utilitarian for future agriculture, largely ignoring current social and cultural dimensions (Ford-Lloyd \& Jackson, 1986; Frankel \& Soule, 1981; Srinivasan, 2010). Under this agenda, they promote the idea that genetic resources are a common heritage allowing everyone free access, even as they largely ignore the contribution of Indigenous people who developed and maintained crop biodiversity (Mooney, 1983).

These differing conceptions of crop diversity and its implications have led to conflicts between groups that represent farmers' and plant breeder's rights (Kloppenburg \& Kleinman, 1988). Thus early on, many crop scientists (Frankel, 1988; Kawano, 2003) were proposing multidisciplinary approaches involving, for example, a combination of research on biological evolution with research on the social implications of diversity management.

Seed systems are often divided into formal and informal or local systems (Almekinders \& Louwaars, 1994). A seed system encompasses a range of activities, including production, saving, distribution, certification and sales, as well as a variety of institutions that support these activities. An informal system mainly deals with the supply of seeds derived from non-certified local or traditional (open-pollinated) varieties that have been created through seed production or exchange by farmers. A formal system aims to provide seed certification, improve varieties (hybrids) and ensure supply under the control of a government body.

Thus, in traditional agriculture, farmers continue to engage in seedsaving practices (McGuire \& Sperling, 2016). In industrialised agriculture, breeding and seed supply are mainly undertaken by governments and/or seed corporations, and farmers are generally obliged to purchase seeds every year.

Many governments have promoted seed-provision systems of the latter kind, based on 'scientific' evidence of more efficient production (Biggs, 2008). Yet in local systems, crop varieties are developed under specific regional climatic and soil conditions; their genotypes are particularly suited to these conditions, and not necessarily to those of other regions. Such varieties tend also to be woven into local culture, customs and livelihoods in ways that other varieties within the same species cannot replicate (Suge, 1987). Additionally, numerous farmers and hobby gardeners continue to collect seeds themselves in both developing and developed countries, including Japan (see Chapters 4-6). 


\subsection{The Diversification of Debates on Seed Systems and Governance}

Perspectives on seed governance among various actors, including researchers, differ widely and often conflict: traditional vs modern, subsistence vs commercial, local vs global, small- vs large-scale frameworks. The failure of the current food and agriculture system has made these conflicts unavoidable (Duncan et al., 2019; Rosset \& Altieri, 2017). However, strict application of any one framework may hinder the development of more sustainable and resilient systems unless attention is paid to the diverse mechanisms supporting seed resilience in each community. Both global and local approaches are important, for instance, but need to be evaluated differently.

Seeds as commons is a concept advocated by many seed activists, including Vandana Shiva (2020). Globally, such a commons demands the inclusion of diverse stakeholders- not only traditional players from public and private institutions, but also members of grassroots organisations, and farmers themselves. The concept is based on the framework of the 2001 International Treaty on Plant Genetic Resources for Food and Agriculture, or ITPGRFA, which promotes plant genetic resource conservation and protects farmers' rights to a fair share of any benefits arising from their use (Frison, 2018).

Indeed, many studies link farmers' rights, seed and food sovereignty, and 'right to food' frameworks to grassroots seed-saving activities, as explained in Chapter 2. The ITPGRFA clearly recognises the concept of farmers' rights as a counterweight to excessive protection of breeders' rights (Andersen, 2008; Esquinas-Alcazar et al., 2013). Achieving collaboration and harmonisation across different activities among diverse stakeholders is critical to ensuring sustainable, resilient seed provision and procurement (Nishikawa, 1990). A diversity of stakeholders is inevitable, given the range of different functions and facilities needed if both conservation and sustainable use are to succeed. Research must therefore encompass more than seed provision and procurement mechanisms, and involve stakeholders working together with others, especially farmers-the most important group in the context of seeds (Chambers, 2005; Neef \& Neubert, 2011; Scoones, 2015).

There are many kinds of seed sourcing that cannot be simply explained in terms of single frameworks of seed governance as described above, such as traditional or modern. (These will be explored in subsequent chapters.) 
Even when formal systems predominate, many farmers still use seeds originating in both informal and formal systems and obtain through purchase, self-saving or exchange (Coomes et al., 2015). And some private companies are in close contact with peasant farmers, enabling them to tailor seed sales to varieties suitable for their farms. By using these perspectives to evaluate seed systems in rural Japan, elsewhere in Asia and beyondwhere livelihoods are deeply rooted in the understanding of surrounding nature and humankind as a part of it-we can add nuance to conceptualisations of agroecology and food sovereignty and enable more resilient seed governance.

As explained in Chapter 2, policies that apply the tenets of agroecology and sovereignty have ultimately helped in transforming highly industrialised, globalised and increasingly unsustainable and fragile food and agriculture systems into more sustainable and resilient ones (Anderson et al., 2020; Levidow et al., 2014; Pimbert, 2018). Jessica Duncan and colleagues (2019), in promoting agroecology research, state: 'We continue to think deeply about our theories of change, our values and principles, and the different roles that we can and do play in enabling agroecology transformations in the food sovereignty movement at large'. Colin Anderson and colleagues (2020) meanwhile assert that bottomup forms of governance and the self-organisation of communities have the potential to enable transformation for sustainability. Various forms of seed activism also exist in Europe, South America and other regions (Peschard \& Randeria, 2020).

Anderson and colleagues suggest that approaches that co-opt or disable bottom-up processes, which are often deployed by governments or corporations, should be avoided. As the core ideas of agroecology and food sovereignty reflect the principles of endogenous development, those principles inevitably enrich any discussion of agroecological transformation. However, endogenous development theory clearly embraces the coexistence of a diversity of systems; and if any model or frame, such as agroecology, is to be widely applied, it needs to be done carefully, given the range of conditions across locales in both Asian and Western contexts.

\subsection{Endogenous Development Theory: A 'Third SySTEM' FOR UNDERSTANDING DEVELOPMENT}

The concept of endogenous development was first identified in the report Development and International Cooperation, which was submitted by 
the Hammarskjöld Foundation to the UN General Assembly in 1975 (Dag Hammarskjöld Foundation, 1975). The report states: 'If the goal of development is human development that aims at the liberation and self-development of man as an individual or as a social being, that development must be endogenous in each social community'.

At around the same time, Kazuko Tsurumi began to apply the concept of endogenous development to specific cases in China and Japan. One of her foci was communities affected by Minamata disease, a severe neurological disease caused by methylmercury poisoning that was first discovered in Minamata, Japan, in 1956 and linked to industrial waste (Tsurumi, 1989, 1996). As one of the foremost proponents of endogenous development theory, Tsurumi set out to define its key elements.

First, endogenous development is specifically associated with certain values, in direct contrast to the standardised or generalised process of modernisation theory, which tends to take a neutral stance on values. (The German sociologist Max Weber was among the first to theoretically codify the transition from traditional to modern society.) Tsurumi states that whereas modernisation theory tends to generalise the process of transition regardless of historical, social and cultural distinctions, endogenous theory focuses on specific societies, is less abstract and is more oriented towards local communities. While any approach applying endogenous development has a common goal-achieving wellbeingTsurumi's formulation posits a number of ways to achieve that, and a range of societal models that might be more likely to enable these processes, as well as other changes that might ensue, such as emergence of different key persons for development.

Second, endogenous development theory emphasises the importance and possibility of mutual exchange. Although endogenous development takes place simultaneously in many localities on a global scale, the kind of development varies; and further, each kind can become a model for other forms of development. In the 1970s, for example, people in Minamata exchanged experiences with Indigenous communities in Canada who had also been affected by mercury poisoning. Despite living under completely different economic, social, cultural and political conditions, the two groups shared ideas how corporate interests and government pressure had severely undermined their dignity and created health crisis and community collapse. This exchange led to involvement of physicians to refine the diagnostics. 
The third element Tsurumi isolated is that a region is an ideal unit for endogenous development, at least in theory. It is a smaller unit than a nation, but not necessarily contained within one nation-such as the Basque Country, which straddles the border of Spain and France.

Fourth, endogenous development rests on a 'third system' of power, distinguishing it from other development theories, which tend to refer to political power as the most important, followed by economic power. This third system focuses not on seeking to change existing political and economic power structures, but rather to encourage locals to have their say and act autonomously within them.

Finally, Tsurumi stressed the importance of tradition. That is, institutions and norms well accepted by people within the designated regions, and comprising three aspects: a structure of awareness, social relations and practical techniques that express the dynamic nature of tradition.

In understanding Tsurumi's conceptualisation of endogenous development, her experience in Minamata reveals much. She visited four communities in the city where many had suffered from Minamata disease. She and her group conducted interviews with study group members, rather than using questionnaires or quantitative data collection methods. From their findings, Tsurumi drew two key conclusions (Tsurumi, 1989, 1996). One was that Minamata disease provided the most extreme case of certain negative aspects of centralised and corporate-led modernisation; the other was that in terms of endogenous development, the actors were people who had suffered from those negative impacts, enacted by the government and certain enterprises.

Tsurumi also developed the concept of autonomous rehabilitation. In the case of Minamata disease, the destruction of nature through rampant industrialisation and pollution affected people not only externally-that is, in their relationship with nature and with other people. It also had an internal impact, on their physical and spiritual health and dignity. Autonomous rehabilitation enabled healing in both respects. When people with the disease realised the limitations of modern medicine in tackling the damage they had suffered, they decided to rehabilitate themselves by deploying their own capabilities and creativity (see Box 3.1). Tsurumi's view of society as multi-faceted posits that transformation cannot be unilateral; that in turn provides a stimulus for finding diverse and inclusive ways of developing relationships between nature and humanity in relation to seed governance. 


\section{Box 3.1: Kazuko Tsurumi's Case Study in Minamata: The Findings}

Towards the end of the 1970s, Tsurumi selected three people with differing attitudes towards nature, and towards the institutions implicated in the Minamata disaster, to examine their personal rehabilitation and that of the Minamata community. She identified the approaches observed in these three individuals as confrontational-integrative, non-confrontational fusionist, and non-confrontational and integrative.

- The actor whose approach was confrontational-integrative organised a self-help group of people with Minamata disease, and filed lawsuits against the company involved, the local government and eventually the national government. He also asserted the necessity of engaging in direct negotiation with the company's president.

- The actor favouring the non-confrontational fusionist approach focused on healing and rehabilitation by immersing in nature, specifically through local activities such as fishing, as well as engaging more closely with her neighbours.

- The non-confrontational integrative actor initially mobilised actively against the company and the public authorities involved. After attending a UN Human Environmental Conference in Stockholm in his wheelchair, however, he became aware of other people affected by mercury poisoning - in countries such as Canada and Indonesia-and began to communicate with them as co-sufferers.

Tsurumi described these creative approaches as demonstrating three layers of social change, seeking a return to an idealised past, cure and rehabilitation focused on both nature and self, and renovative creation of balance in which conflicting ideas coexist simultaneously (Tsurumi, 1987).

Source Originally Presented at the Ninth Meeting of the International Society for the Study of Behavioral Development, 13 July 1987, Tokyo.

There are other definitions and applications of endogenous development theory. One core point of debate has been whether endogenous development can be integrated into government policy, which is generally perceived as the imposition of edicts or measures on communities by an external institution. In such cases, the argument goes, endogenous development processes could no longer be considered properly endogenous, and would generate unresolvable tension between enforceable policy and local people's spontaneous judgement or practice (Matsumiya, 2001), which is independent of influence from outside with power. If authority 
is exercised uniformly over all communities and/or individuals, it could be seen as conflicting with local autonomy.

Locally specific issues arising in different localities need constant reevaluation, and endogenous development should be considered as one potentially valuable tool in understanding how conflicting practices and theories can coexist.

In relation to endogenous development, Hisashi Nakamura (1989) theorised that agriculture can be seen as a symbiotic relationship between humans and non-humans, and is thus tied to the specific space and time in which symbiosis is created and maintained. In this book, especially Chapters 5, 7, and 10 about Japan and East Asia, contributors elaborate on this relationship to expand current understanding of agroecology by integrating it with components of endogenous development theory.

Readers of this book seeking to understand endogenous development better should note that relevant views have been theorised in the sustainable livelihoods approach (SLA), which was widely adopted by the former UK Department for International Development from the 1990s (Scoones, 2015). The SLA emphasises diversity in its analysis of livelihoods. In this it is assumed that, while those from outside a community may provide assistance, it is local people who are trying to diversify their lifestyles by applying a strategy prioritising sustainable survival.

In the SLA, the starting point for development, or resource governance, is that such governance is sustainable only when rural people spontaneously participate in it, rather than be compelled to do so by external institutions. Indeed, as Ian Scoones has noted (2015), the 'failure of agricultural and rural development to date has been largely due to the uniform top-down policies of governments and aid agencies (focused on economic growth)'. Although the rationale is different, the SLA is similar to endogenous development theory in according a lesser role to outside agencies in community development than to the communities themselves.

\subsection{Approaches to Exploring Seed Governance and Expanding Perspectives on Seed Sovereignty}

Farmers are key players in conserving biocultural diversity-that is, the integration of farming into people's livelihoods. In developing countries, many farmers do not necessarily prioritise increased crop yields or profits; they also consider cultural values, avoidance of risks (such as drastic harvest failures), and personal preferences in crop varieties. Long before 
the concept of seed sovereignty arose within political debates, farmers and local people tended to see crop diversity and seed production as just aspects of their everyday work.

Moreover, not all people who procure and supply seeds in Japan and other Asian countries base their farming practice or activities on specific rights to use and control resources. Their approaches and practices are derived not from politics but from a kind of intuitive understanding, as farmers, of their role in stewarding regional ecology. That process expresses their own endogenous development, and provides the foundation of their approach to seed care. For many of them, there is no contradiction between concepts of property rights and informal, day-today applications of traditional tacit knowledge on seeds: the two can exist in parallel (Rival, 2018; Nakazora, 2019).

Each chapter of this book looks at the approaches of ordinary people who do not think in terms of sovereignty over seeds. Sam Gray and Raj Patel (2015), among others, have claimed that ideas of food sovereignty have the potential to liberate people and communities that are otherwise deeply dominated by unsustainable food and agriculture systems. However, introducing the concept of seed sovereignty to seed governance where people have emphasised commitment and care rather than rightsbased thinking may run the risk of generating new forms of oppression. A sovereignty-based approach may inadvertently pressure people who have managed their resources without thinking in such terms to accept the political perspective of sovereignty as necessary discourse (Anderson et al., 2020).

All the contributors of this book seek to encourage a greater awareness and acceptance of agroecology and food sovereignty. At the same time, they honour the fact that many people hesitate to introduce such ideas into local communities and institutions without first understanding and safeguarding local stakeholders' evolved approaches to governing resources.

These concerns can be illustrated by debates that took place in conferences of the International Council on Monuments and Sites (ICOMOS) during the 1990s, where delegates and members wrangled with the concept of authenticity vis-à-vis cultural heritage and cultural diversity (Stovel, 2008). The result was an important declaration, the Nara Document on Authenticity. Before 1992, when Japan became a member of the World Heritage Convention (which had been adopted by the General Conference of the United Nations Educational, Scientific and 
Cultural Organization, or UNESCO, in 1972), the issue of heritage authenticity was mainly discussed in the context of European stone structures. Wooden structures that are periodically rebuilt based on traditional designs and methods - such as the Shinto Ise Grand Shrine in Japanwere not recognised as part of authentic heritage. (Since each of more than 700 thousand pieces of construction materials need to be examined for the authenticity every twenty years under UNESCO scheme, the Shrine decided not to be registered as a World Heritage. However, another site, Shirakawa, with wooden houses whose materials for thatches are gathered in the traditional way was registered because it is the way itself that is recognised as authentic.)

The Nara Document on Authenticity (ICOMOS, 1994) affirms that cultural heritage diversity exists across time and space and that other cultures and all aspects of their belief systems need to be respected (Article 6). Specifically, Article 11 states:
All judgments about values attributed to cultural properties as well as the credibility of related information sources may differ from culture to culture, and even within the same culture. It is thus not possible to base judgments of values and authenticity within fixed criteria. On the contrary, the respect due to all cultures requires that heritage properties must be considered and judged within the cultural contexts to which they belong.

Seeds are tangible substances forming an essential part of biocultural heritage and diversity within a sustainable seed governance system, which with food sovereignty forms an integral component of a sustainable and resilient society. UNESCO clearly recognises the importance of specific contexts in time and space, and of values recognised and asserted by parties concerned, while accepting the universal value of world heritage. Thus, when applying evaluation criteria and processes developed by outsiders, it is necessary to ensure meaningful debates through the inclusion of relevant stakeholders.

Seeking to promote one ideology from one specific society as authoritative is antithetical to diversity and inclusion. This book seeks to promote those values, which also lie at the core of the UN Sustainable Development Goals. Each chapter provides valuable information on the actors, processes and methods that are currently involved in the conservation and utilisation of crop genetic resources, and on the diversity of seeds in different contexts. These cases illustrate the mechanisms needed to 
prevent new forms of oppression directed towards local stakeholders, and how autonomy and respect can be secured as critical components of sovereignty.

\section{REFERENCES}

Almekinders, C., \& Louwaars, N. (1994). Local seed systems and their importance for an improved seed supply in developing countries. Euphytica, 78(3), 207-216. https://doi.org/10.1007/BF00027519

Andersen, R. (2008). The international treaty on plant genetic resources for food and agriculture with the international undertaking on plant genetic resources. In R. Andersen (Ed.), Governing agrobiodiversity: Plant genetics and developing countries (pp. 87-115). Ashgate.

Anderson, C. R., Bruil, J., Chappell, M. J., Kiss, C., \& Pimbert, M. P. (2020). From transition to domains of transformation: Getting to sustainable and just food systems through agroecology. Sustainability, 11(19), 1-28. https://doi. org/10.3390/sul1195272

Biggs, S. (2008). The lost 1990s? Personal reflections on a history of participatory technology development. Development in Practice, 18(4-5), 489-505.

Chambers, R. (2005). Ideas for development. Routledge.

Coomes, O. T., McGuire, S. J., Garine, E., Caillon, S., McKey, D., Demeulenaere, E., Jarvis, D., Aistara, G., Barnaud, A., Clouvel, P., Emperaire, L., Louafi, S., Martin, P., Massol, F., Pautasso, M., Violon, C., \& Wencélius, J. (2015). Farmer seed networks make a limited contribution to agriculture? Four common misconceptions. Food Policy, 56, 41-50. https://doi.org/10. 1016/j.foodpol.2015.07.008

Dag Hammarskjöld Foundation. (1975). The 1975 Dag Hammarskjöld Report on Development and International Cooperation. Dag Hammarskjöld Foundation. Retrieved July 26, 2021, from www.daghammarskjold.se/publication/1975dag-hammarskjold-report-development-international-cooperation/

Duncan, J., Claeys, P., Rivera-Ferre, M. G., Oteros-Rozas, E., Van Dyck, B., Plank, C., \& Desmarais, A. A. (2019). Scholar-activists in an expanding European food sovereignty movement. The Journal of Peasant Studies, 1-26. https://doi.org/10.1080/03066150.2019.1675646

Esquinas-Alcazar, J., Hilmi, A., \& Noriega, I. (2013). A brief history of the negotiation on the International Treaty on Plant Genetic Resources for Food and Agriculture. In M. Halewood, I. Noriega, I., \& S. Louafi (Eds.), Crop genetic resources as a global commons (pp. 135-149). Routledge.

FAO. (1996). Report on the state of the world's plant genetic resources for food and agriculture. FAO.

Ford-Lloyd, B., \& Jackson, M. (1986). Plant genetic resources: An introduction to their conservation and use. Edward Arnold Ltd. 
Frankel, O. H. (1988). Genetic resources: Evolution and social responsibilities. In J. K. Kloppenburg (Ed.), Seeds and sovereignty: The use and control of plant genetic resources (pp. 19-46). Duke University Press.

Frankel, O. H., \& Soule, M. E. (1981). Conservation and evolution. Cambridge University Press.

Frison, C. (2018). Redesigning the global seed commons: Land and policy for agrobiodiversity and food security. Routledge.

Grey, S., \& Patel, R. (2015). Food sovereignty as decolonization: Some contributions from Indigenous movements to food system and development politics. Agriculture and Human Values, 32, 431-444. https://doi.org/10.1007/s10 460-014-9548-9

Harlan, J. R. (1992). Crops and Man (2nd ed.). American Society of AgronomyCrop Science Society. ISBN 978-0891181071.

ICOMOS. (1994). The NARA document on authenticity. Retrieved July 26, 2021, from https://www.icomos.org/en/charters-and-texts/179-articles-enfrancais/ressources/charters-and-standards/386-the-nara-document-on-aut henticity-1994

Kawano, K. (2003). Thirty years of cassava breeding for productivity: Biological and social factors for success. Crop Science, 43, 1325-1335.

Kloppenburg, J., \& Kleinman, D. (1988). Plant genetic resources: The common bowl. In J. K. Kloppenburg (Ed.), Seeds and sovereignty: The use and control of plant genetic resources. Duke University Press.

Levidow, L., Pimbert, M. P., \& Vanloqueren, G. (2014). Agroecological research: Conforming-or transforming the dominant agro-food regime? Agroecology and Sustainable Food Systems, 38(10), 1127-1155. https://doi. org/10.1080/21683565.2014.951459

Matsumiya, A. (2001). 'Naihatsuteki hatten' wo meguru shomondai, Naihatsuteki hattenron no tenkai ni mukete [Problems dealing with the concept of endogenous development: Searching for an alternative strategy in studies of endogenous development]. Social Welfare Studies, 3(1), 45-54.

McGuire, S., \& Sperling, L. (2016). Seed systems smallholder farmers use. Food Security, 8, 179-195. https://doi.org/10.1007/s12571-015-0528-8

Mooney, P. (1983). The law of the seed: Another development and plant genetic resources. Development Dialogue series, 1-2. Dag Hammarskjöld Foundation.

Nakamura, H. (1989). Technology and autonomous local development movement. In K. Tsurumi \& T. Kawata (Eds.), Endogenous development theory (pp. 215-240). University of Tokyo Press.

Nakazora, M. (2019). Temporalities in translation: The making and unmaking of "folk" Ayurveda and bio-cultural diversity. In K. Omura, J. G. Othuki, 
S. Satsuka, \& A. Morita (Eds.), The world multiple: The quotidian politics of knowing and generating entangled worlds (pp. 140-154). Routledge.

Neef, A., \& Neubert, D. (2011). Stakeholder participation in agricultural research projects: A conceptual framework for reflection and decision-making. Agriculture and Human Values, 28, 179-194. https://doi.org/10.1007/s10 460-010-9272-Z

Nishikawa, Y. (1990). Institution for plant genetic resources in developing countries. Papers in Development Administration No. 37. University of Birmingham.

Peschard, K., \& Randeria, S. (2020). 'Keeping seeds in our hands': The rise of seed activism. The Journal of Peasant Studies, 47(4), 613-647. https://doi. org/10.1080/03066150.2020.1753705

Pimbert, M. (2018). Democratizing knowledge and ways of knowing for food sovereignty, agroecology and biocultural diversity. In M. Pimbert (Ed.), Food sovereignty, agroecology and biocultural diversity: Constructing and contesting knowledge (pp. 259-321). Routledge.

Rival, L. (2018). An anthropological lens on property and access: Gudeman's dialectics of community and market. In F. Girald \& C. Frison (Eds.), The commons, plant breeding and agricultural research: Challenges for food security and agrobiodiversity (pp. 147-158). Routledge.

Rosset, P. M., \& Altieri, M. A. (2017). Agroecology: Science and politics. Fernwood Publishing.

Scoones, I. (2015). Sustainable livelihoods and rural development. Agrarian Change \& Peasant Studies Series. Fernwood Publishing.

Shiva, V. (2020). Reclaiming the commons; biodiversity, indigenous knowledge, and the rights to Mother Earth. Synergetic Press.

Srinivasan, C. S. (2010). Plant breeders' rights and on-farm conservation. In S. Lockie \& D. Carpenter (Eds.), Agriculture, biodiversity and markets: Livelihoods and agroecology in comparative perspective (pp. 61-76). Earthscan.

Stovel, H. (2008). Origins and influence of the Nara document on authenticity. APT Bulletin, 39(2/3), 9-17.

Suge, H. (1987). Ikushu no genten [Real base of plant breeding]. Nosanhyoson Bunka Kyokai.

Tsurumi, K. (1987). New lives: Some case studies in Minamata. In K. Tsurumi (Eds.), The adventure of ideas: A collection of essays on patterns of creativity \& a theory of endogenous development. Japanime, Manga University. Retrieved July 26, 2021, from www.howtodrawmanga.com/products/tsurumi

Tsurumi, K. (1989). Naihatsu-teki Hatten-ron no keifu [A genealogy of endogenous development]. In T. Kawata \& K. Tsurumi (Eds.), Naihatsu-teki Hatten-ron [Endogenous development]. Iwanami Shoten. 
Tsurumi, K. (1996). Genealogy of endogenous development theory. In K. Tsurumi \& T. Kawata (Eds.), Endogenous development theory (pp. 43-64). University of Tokyo Press.

Open Access This chapter is licensed under the terms of the Creative Commons Attribution 4.0 International License (http://creativecommons.org/licenses/ by $/ 4.0 /)$, which permits use, sharing, adaptation, distribution and reproduction in any medium or format, as long as you give appropriate credit to the original author(s) and the source, provide a link to the Creative Commons license and indicate if changes were made.

The images or other third party material in this chapter are included in the chapter's Creative Commons license, unless indicated otherwise in a credit line to the material. If material is not included in the chapter's Creative Commons license and your intended use is not permitted by statutory regulation or exceeds the permitted use, you will need to obtain permission directly from the copyright holder.

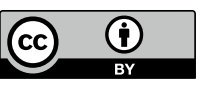

